\title{
Research on Work Zone Traffic Organization of Reconstruction and
}

\section{Extension of Arterial Highway}

\author{
Wu Keman ${ }^{1, a}$, Zhao Nale Kab $^{1, b}$ \\ ${ }^{1}$ Research Institute of Highway, Ministry of Transportation, China \\ a21766104@qq.com, b1597434233@qq.com
}

\begin{abstract}
Key words: Traffic Organization; Arterial Highway; Work Zone; Reconstruction and Extension of Arterial Highway

Abstract: Arterial Highway is usually the only highway of its region. Once reconstructed and extended, it will has significant impact on regional traffic. So, research on traffic organization during reconstruction and extension of arterial highway appears particularly important. Aiming at the special situation which standards don't involve, such as detour, construction of overpass, traffic organization of entrance and exit of factories during the construction etc., this paper studies special traffic organization questions on above-mentioned important locations of reconstruction and extension of arterial highway based on a reconstruction and extension of a second grade Highway in Hebei Province as an example. Feasible traffic organization plans are raised to share some experiences in the hope of mutual encouragement with experts and colleagues.
\end{abstract}

\section{Introduction}

Arterial highways play an irreplaceable role in the regional highway network. Some of them are often the only highways in the area, and along the highway there are often factories and shops, where heavy trucks need to come in and out or stay. Traffic volume is very huge under normal traffic conditions. Once the arterial highway is reconstructed and extended, the regional transportation will be greatly affected. Therefore, the study of traffic organization during the reconstruction and extension of arterial highway is particularly important. In the current "Safety Work Rules for Highway Maintenance ", there is no explicit provision for traffic organization and facilities layout of highways through villages with dense accesses. Taking a secondary highway in Hebei Province as an example, this paper aims at the research and practice of the traffic organization scheme for key segment and key process during upgrading of the second grade highway into the first grade. The purpose is to minimize the impact of the construction on highway traffic operation, and to further improve traffic safety during construction period.

\section{Project Overview}

The whole project of upgrading of the second grade highway is located in Tangshan in Hebei province. The total mileage of the project is about $57 \mathrm{~km}$; there are 6 bridges, 24 small bridges, 1 toll station and 1 management office. The whole project is constructed according to the technical standard of the first grade highway, the design speed is $80 \mathrm{~km} / \mathrm{h}$, the highway is reconstructed on the basis of the original second grade highway, and the construction does not interrupt traffic. The second grade highway is an important access in the region, which goes through the village. There are many factories and mines and accesses along the Highway. The road side interference is serious. There are no other alternative roads during the construction period. The reconstruction of the original second grade highway will lead to a serious decline in the capacity and service level of the road and serious potential danger of traffic. Therefore, in the process of reconstruction, how to ensure the traffic operation to minimize the impact of construction on traffic flow and to ensure the traffic safety becomes an urgent problem to be solved. In order to ensure the smooth 
implementation of the project and the smooth highway traffic, the project group makes traffic organization plan with pertinence and feasibility according to the main engineering scale, expansion plan and regional road network etc..

\section{Traffic organization plan design}

Truck proportion of the secondary Highway in normal operating period accounts about $15 \%$. The proportion of motorcycles and agricultural vehicles on the highway section through villages accounted for about $10 \%$. During the period of construction, parts of transit vehicles could take other routes, and most of large-scale trucks go to factories and mines along the highway, which leads to increased proportion of large-scale trucks during the construction, meanwhile, traffic capacity and service level will be severely affected, especially for highway sections through villages. Therefore, traffic organization during the period of construction is the key to reduce congestion and accident rate.

Traditional traffic organization plans, such as four lanes in both directions with a lane closed and four lanes in both directions with one direction closed, etc., can be completed according to the existing national or industrial standards. They have general applicability, and aren't studied in the paper. Here intends to combine the characteristics of the secondary highways and make traffic organization plan with the special control point on the highway section as an example.

\section{Detours}

When bridges are constructed, if the water under the bridge is not deep and surrounding land is flat, building traffic detour is an optimal traffic organization plan because of the limitation of bridge deck width. While considering economy, building traffic detour is more expensive and costs longer time than using existed roads with half construction and half traffic operation. However, considering the limit of the width of the bridge construction area, it is difficult to carry out the large-scale mechanized construction. In addition, the factories and mines along highway, which goes through the village, give strong support on regional economic, interrupting traffic would bring huge losses on regional economy. Therefore, after the measurement and consideration of various factors, the project group decides to adopt the traffic organization plan of building traffic detour.

In the construction of No.1 Bridge, building traffic detour is adopted, as shown in figure 1. As driving into the detour, the drivers need to operate the steering wheel to veer and adapt themselves to the detour pavement. The detour pavement quality is inferior compared to the original highway, so most drivers will slow down. For security, conventional traffic signs and safety cones should be set. On the start section of the detour, movable guardrails should be set in the middle to separate the two way traffic. And if the start section is near to the work zone, movable guardrails should be set at both ends. Furthermore, construction warning lights ought to be set on the movable guardrails to prevent vehicles from entering the work zone by mistake. When the detour passing through the river, mobile guardrails should also be installed at both ends to prevent large vehicles from turning over into the river at night, and construction warning lights should be set on them, too. 


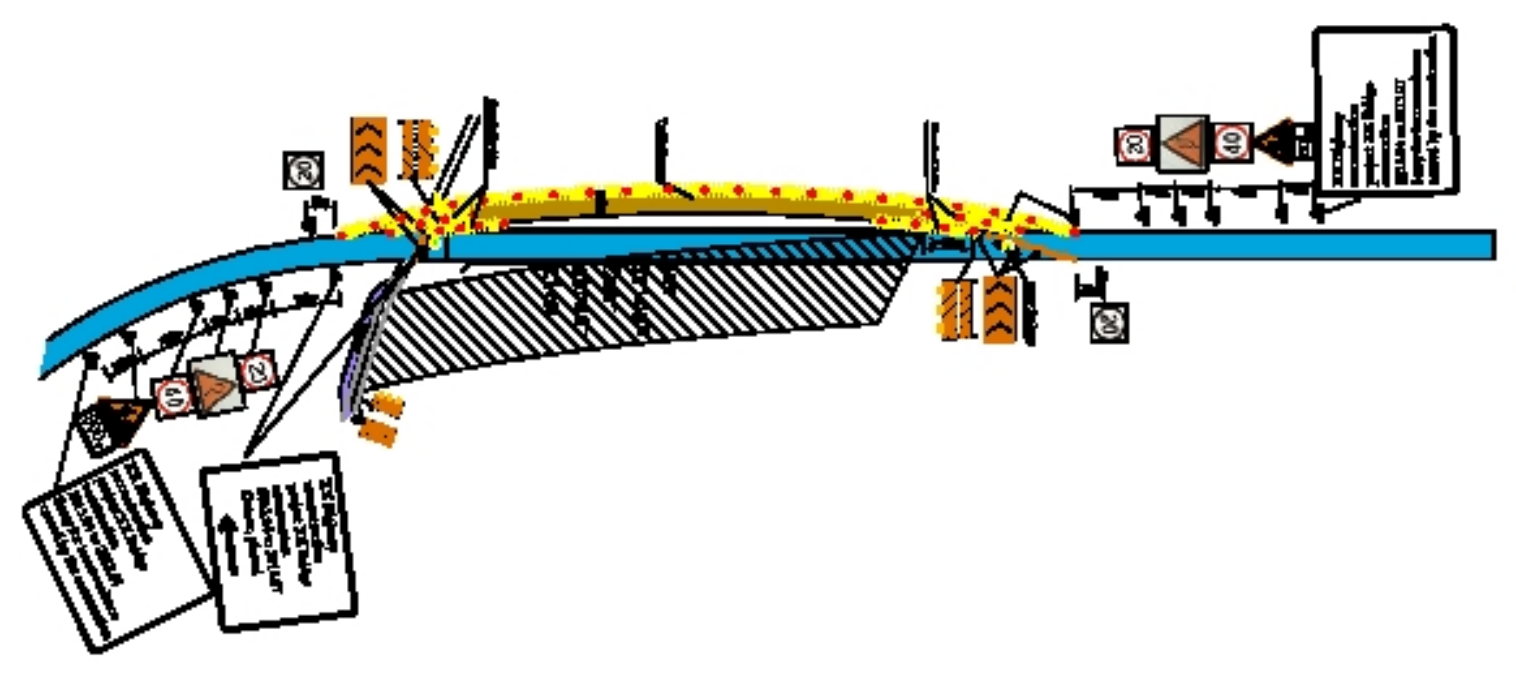

Fig. 1: No. 1 Bridge detour traffic organization plan

The following points are supposed to be noted in the construction of the detour:

1) The work zone should be closed after the detour construction is completed. Both two way traffic should be closed at the same time.

2) Both the detour pavement quality and alignment of the detour have great impacts on traffic efficiency. The maximum longitudinal slope of the detour should not exceed $8 \%$, the minimum curve radius should not be less than $60 \mathrm{~m}$, and the effective driving width should be more than $8 \mathrm{~m}$.

3) Due to the fact that the detour condition is not as good as the original highway, the capacity of the detour would be affected. Attention should be paid to the central separation of the detour, and traffic guidance and protection of the junction between the detour and the original highway. The setting order of traffic facilities is as follow: (1)guardrails and safety cones on the detour, (2)notice signs, guidance signs, rotary fan lamp on the both sides of the work zone, (3)safety cones and guardrails on both sides of the work zone, (4)other signs on both sides of the work zone.

4) The signs setting order is recurred from far away from work zone to work zone.

5) The traffic detour can't be used as construction detour as the same time, and construction vehicles, machineries and materials can still be placed on the original Highway with closed traffic. But construction vehicles shouldn't be parked on the original highway for a long time, machineries should be operated within work zone, materials loading and unloading should also be completed within work zone.

6) The warning lights on the guardrails on both sides of the work zone should stay lit at night.

7) The warning and protection of large vehicles should be paid attention to when building detour on the bridge, and the warning lights on the guardrails on both sides of the detour should be kept on at night.

8) Under the situation of detour traffic (as shown in figure 2), the length of the transition zone can be calculated according to the following formula from "Road traffic signs and markings"(GB5768):

$$
L_{j}=\frac{v^{2} W}{155} \quad(\mathrm{v}<60 \mathrm{~km} / \mathrm{h})
$$

$\mathrm{L}_{\mathrm{j}}$ - the length of the transition zone;

$\mathrm{v}-$ speed limit value, $20 \mathrm{~km} / \mathrm{h}$;

$\mathrm{W}$ - horizontal width of the enclosed area. In the case of one side detour, the width of driveway is $9 \mathrm{~m}$, the width of the detour is $8 \mathrm{~m}$, so $\mathrm{W}=4.5+\mathrm{H}+4$. In the case of two side detours, $\mathrm{W}=4.5+\mathrm{H}$.

When the detour is adopted and the speed limit value is $20 \mathrm{~km} / \mathrm{h}$, the relationship between the 
length of the transition zone $\left(\mathrm{L}_{\mathrm{j}}\right)$ and the horizontal distance $(\mathrm{H})$ of the original road and the detour is shown in table 1.

Table 1: length of transition area under the situation of detour traffic

\begin{tabular}{|c|c|c|}
\hline $\mathrm{H}(\mathrm{m})$ & $\mathrm{L}_{\mathrm{j}}(\mathrm{m})$ (one side detour) & $\mathrm{L}_{\mathrm{j}}(\mathrm{m})$ (two side detours) \\
\hline 5 & 35 & 25 \\
\hline 10 & 50 & 40 \\
\hline 15 & 60 & 50 \\
\hline 20 & 75 & 65 \\
\hline
\end{tabular}

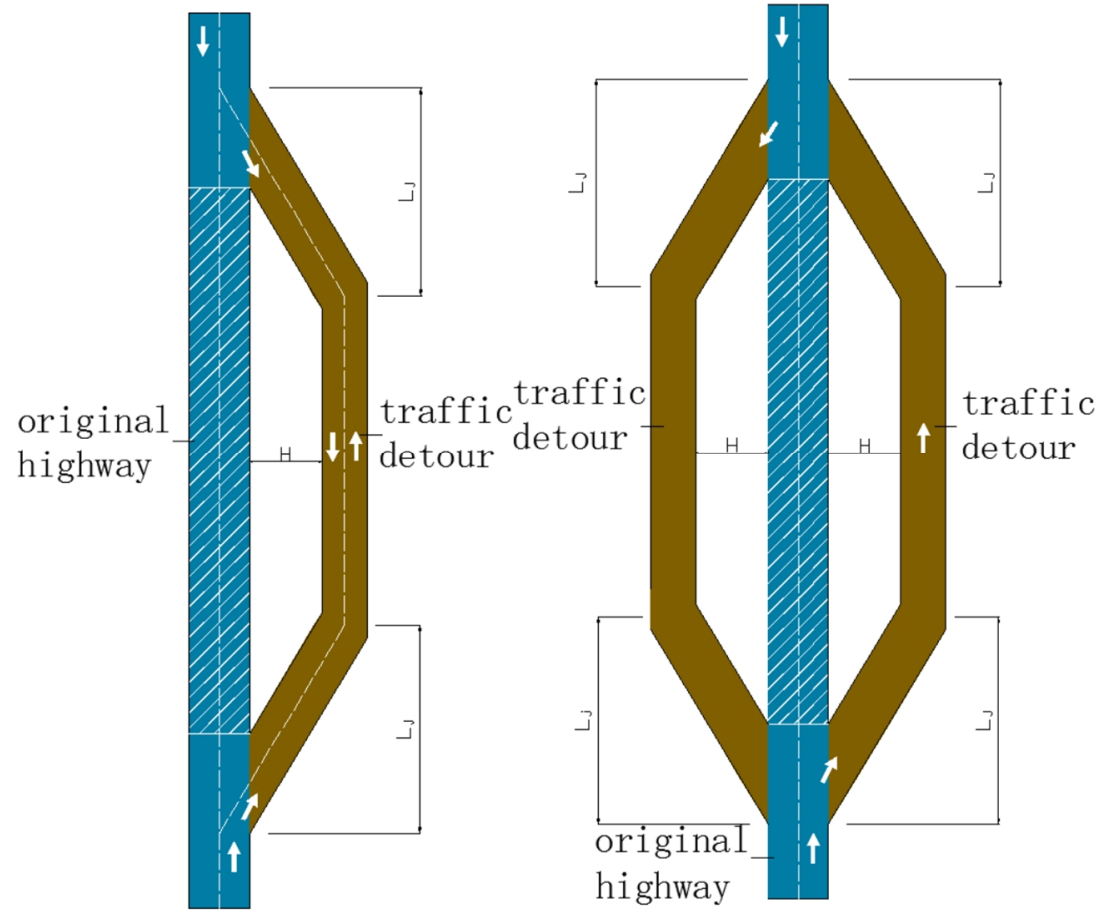

Fig. 2: detour traffic on Highway

\section{Using old highway to pass when one direction of a new highway is under construction}

Old highway is used to pass, when one direction of a new highway is under construction, and after the half is opened to traffic, another half will be built. That is a common way to organize traffic on this highway. As shown in figure 3, in this way, the construction doesn't occupy the road, and it is usually a unilateral construction outside the road. The effect of construction to traffic is relatively small. So the construction signs on the far side of the work zone can be placed after the first speed limit sign and flush with the second speed limit sign. As for the signs setting, in addition to meeting the requirements of standard, the notice signs with black character on a white background should also be set at the appropriate position in each contract section. These signs will tell the construction date and other messages. 


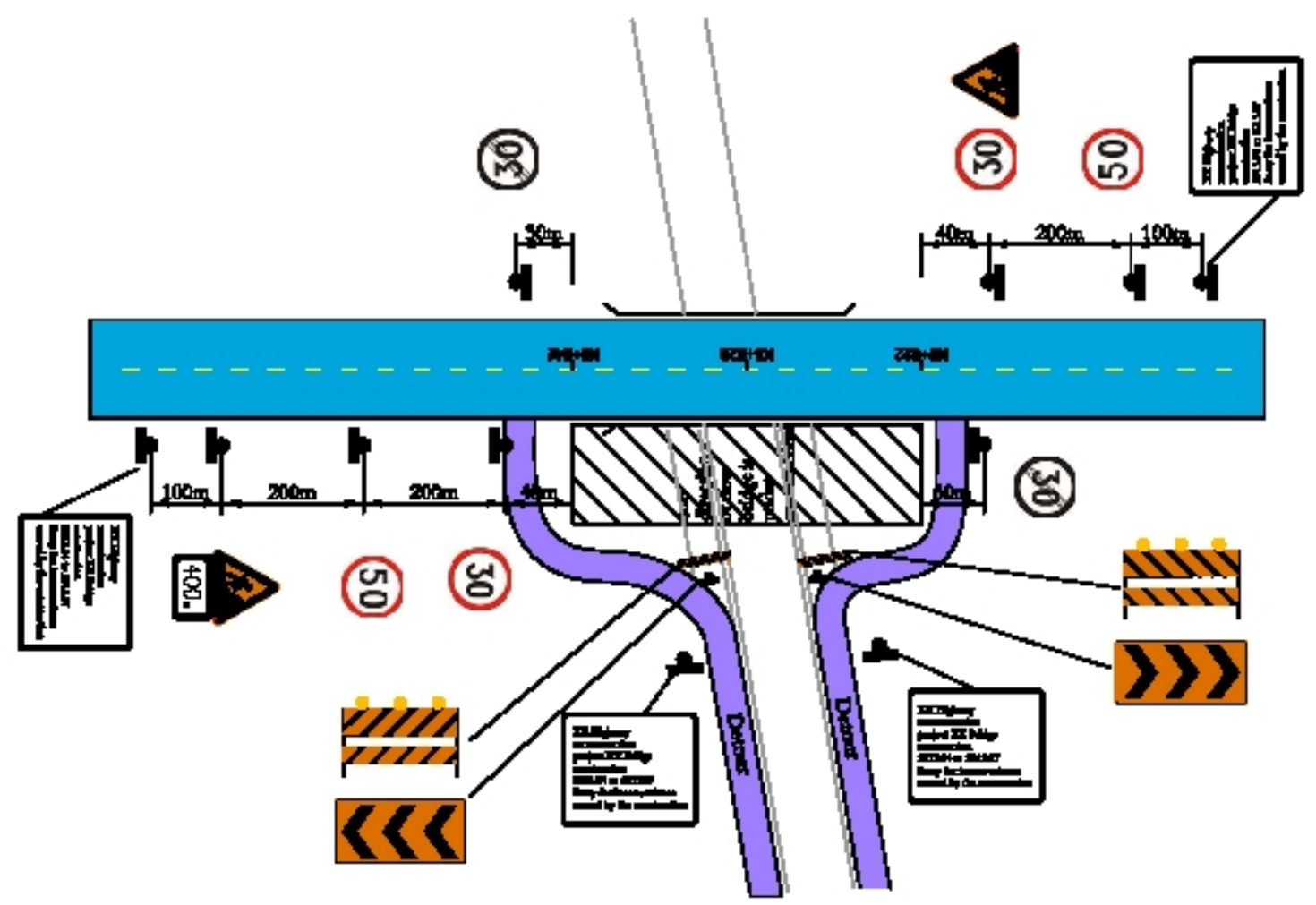

Fig. 3: traffic organization plan of No. 2 Bridge construction using old highway traffic

\section{Traffic organization plan of overbridge construction}

An overbridge is planned for the first grade highway after the reconstruction and extension. And the traffic organization adopts the construction fence, which is commonly used in urban roads, combined with movable guardrails. Considering the difference from urban roads, movable guardrails with anti-collision capability are installed on the adjacent side of the highway to ensure the safety of vehicles and pedestrians.

As shown in figure 4, the construction of overbridge will intrude into the road slightly, so mobile guardrails need to be installed to prevent vehicles from straying into the work zone. The work zone should be closed by construction fence which is more than $1.8 \mathrm{~m}$ of height. And the width of driveway should not be less than $3.25 \mathrm{~m}$ pro lane.

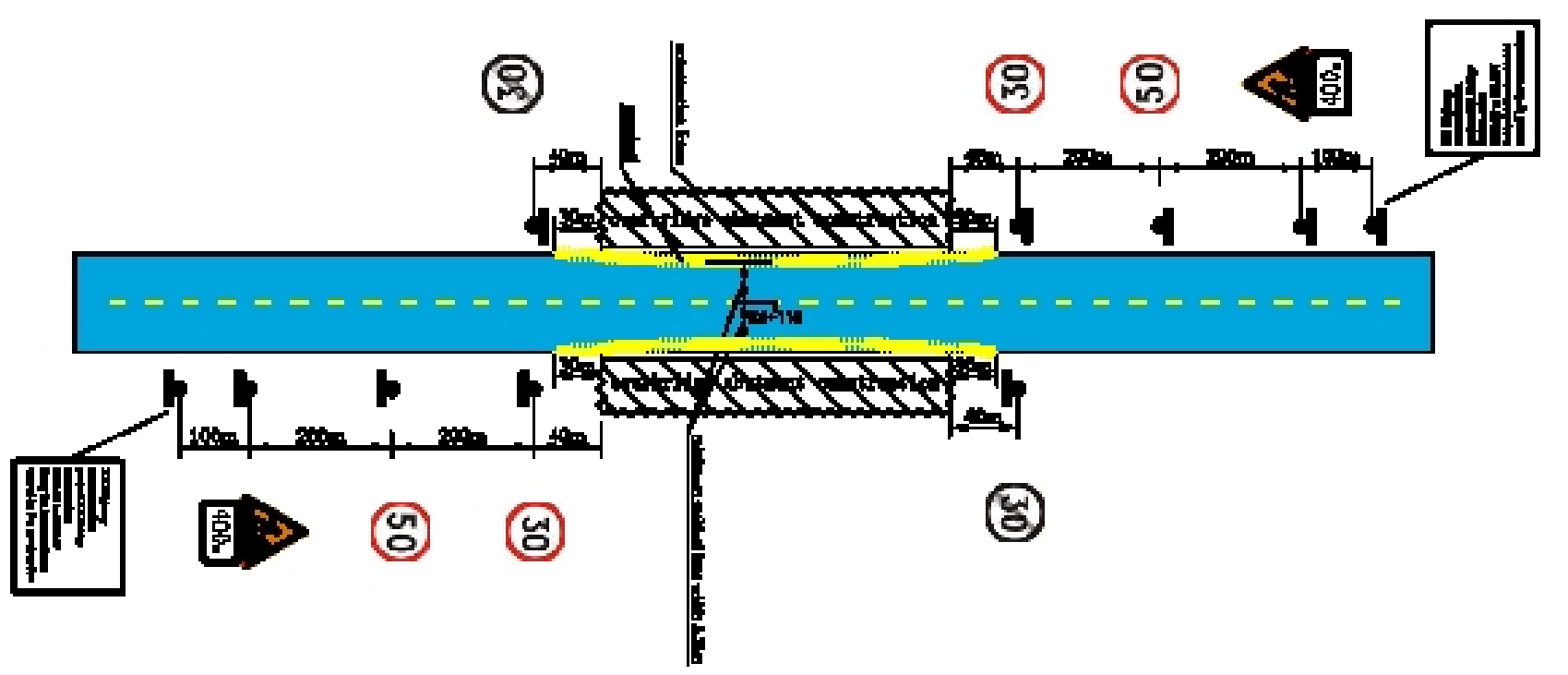

Fig. 4 : Traffic Organization Plan of No. 1 Overbridge Construction 


\section{Diversion design in and out of factories and mines}

Because of the special geographical location, two kinds of traffic organization plans are proposed in order to ensure the normal traffic of vehicles, as shown in figure 5 and figure 6 , when the construction of roadbed in front of the factories' gates along the second grade highway is carried out.

In plan 1, the construction of the road around the gate of the factory should be carried out first. After the completion of the construction, the temporary gate should be built near the original gate, and the construction of the original gate should be carried out finally. In plan 2, the gate of the factory is divided into two parts. The left side of the gate and the surrounding roads are carried out first, and then constructing the right side and the roads around. Plan 1 is suitable for the narrow gate, if the narrow gate is divided into two parts, the trucks can't get in and out smoothly. However, plan 2 is suitable for wide gates, because the large trucks won't be affected in the above situation. Protective screening and scaffold should be set around work zone for security.
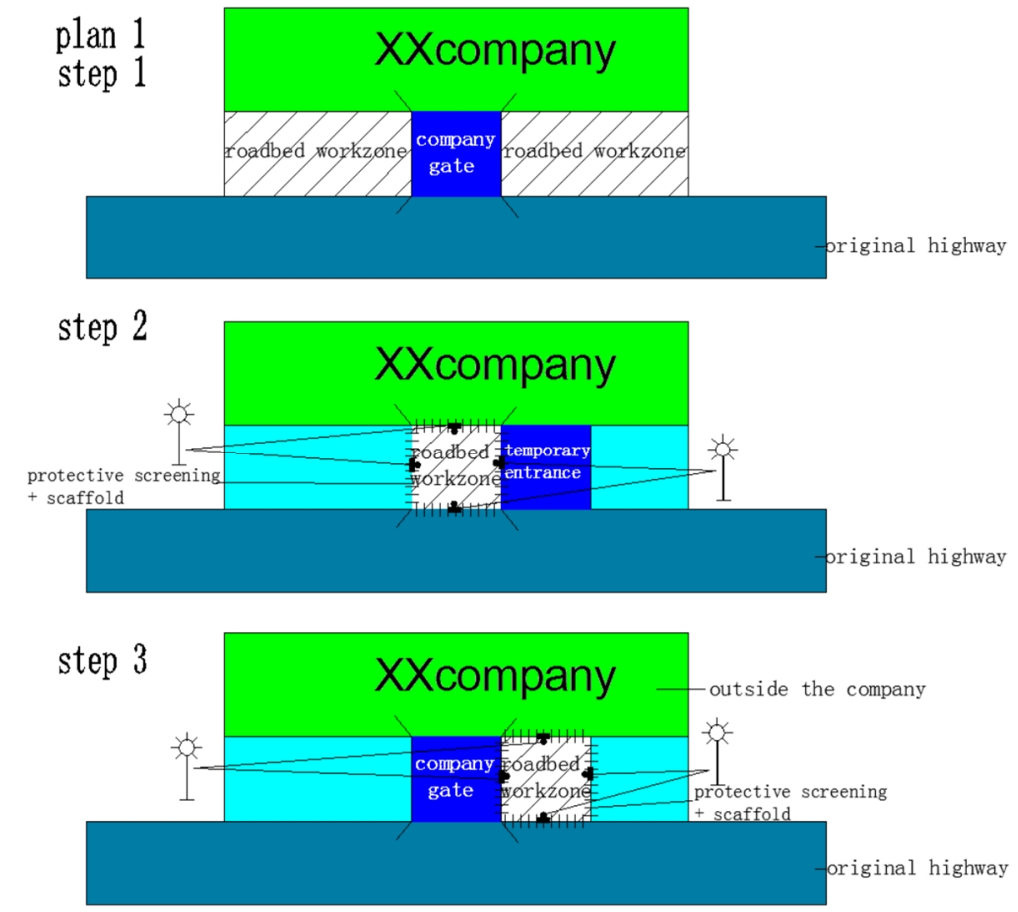

Fig. 5: Traffic Organization Design for Diversion In and Out of Factories and Mines(Plan 1)

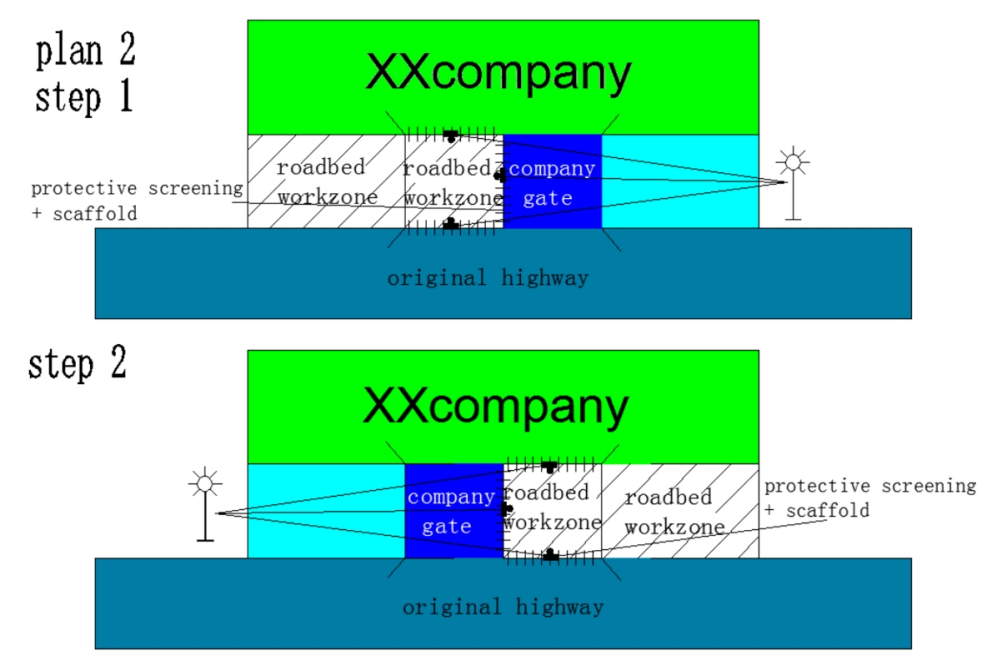

Fig. 6: Traffic Organization Design for Diversion In and Out of Factories and Mines (Plan 2) 


\section{Traffic organization design of pipe culvert construction}

As a second grade highway through village, lots of stores are located on roadside of part of the highway sections, so the roadside space has been very limited before the construction. During the period of pipe culvert construction, in order to minimize the impact on the production and life of residents living along the highway, pedestrian and non-motor vehicle traffic should be guaranteed first. Where conditions permit, it is necessary to ensure the normal the vehicle traffic. The traffic organization design is shown in figure 7 , the positions in purple are traffic detours, both sides of the pipe culvert construction area must be in isolated protection. Protective screening is about $1.2-1.5 \mathrm{~m}$ high, and construction fence is about $1.8 \mathrm{~m}$ high. Reflective signs should be added and the lighting facilities should be kept lit at night.

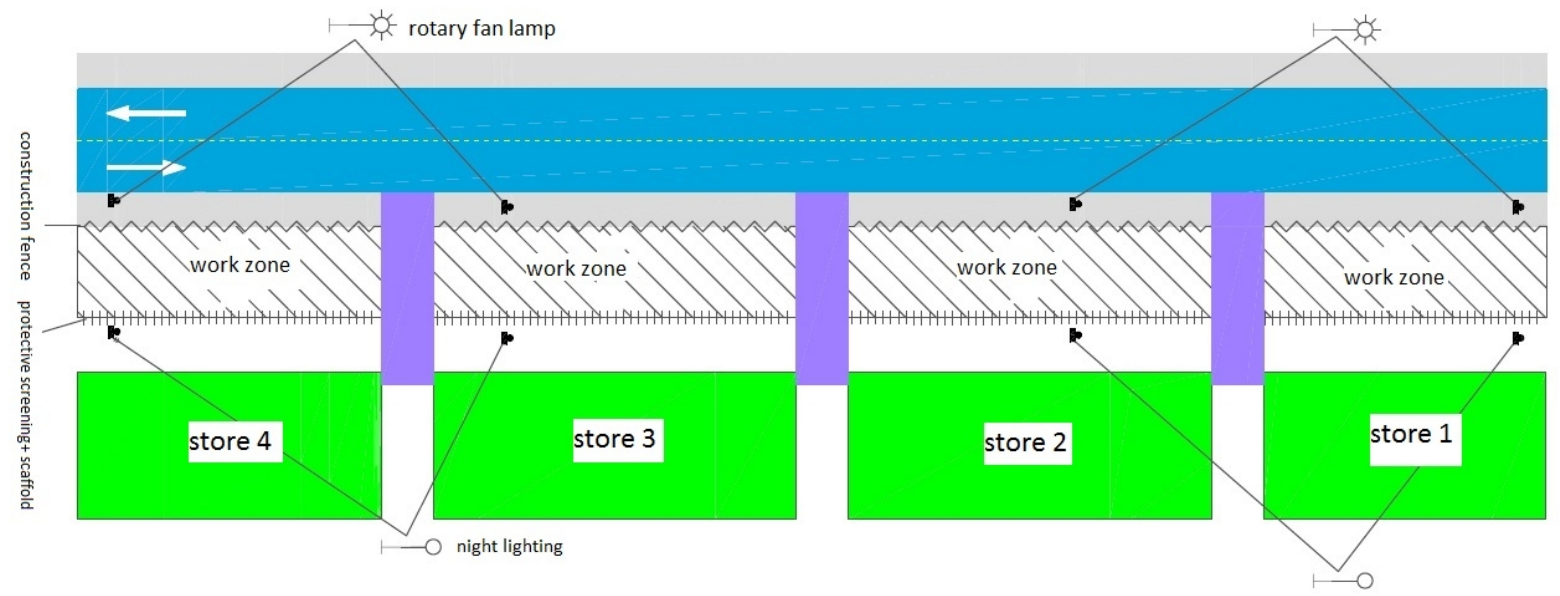

Fig. 7: Traffic Organization Design of Pipe Culvert Construction

\section{Conclusion}

This paper focuses on the traffic organization problems during the reconstruction and extension of a second grade highway, such as traffic detours, using old highway to pass, overbridge construction, diversion design in and out of factories and mines, pipe culvert construction, and then puts forward the corresponding traffic organization plan. These plans are different from the general plans in industry standards, and they are summarized by designers, managers and constructors through many times of communications with each other. After the implementation of the plans, the traffic safety of the construction section is in good condition, and the vehicles are more efficient. The construction has to a very significant extent less influence on the production of enterprises and residents along the route. It is hoped that it will be a useful reference for the traffic organization design of the arterial highway upgrading project.

\section{References}

[1] The Ministry of Transportation of PRC, Safety Work Rules for Highway Maintenance (JTG H30-2015) [S]. Beijing, The People's Communication Publishing Company, august 2004.

[2] PRC National Standard, Road traffic signs and markings (GB5768-2009) [S]. Beijing, China Standards Press, 2009.

[3] The Ministry of Transportation of PRC, JTG B01-2014. Technical Standard of Highway Engineering [S]. Beijing, The People's Communication Publishing Company, 2014.

[4] Liande Zhong, Dezao Hou etc. Traffic Safety Technology for Highway Work Zone, [M]. Beijing, The People's Communication Publishing Company, 2012.

[5] Liande Zhong, Traffic organization technology in construction area of highway reconstruction and expansion project [R]. Beijing, Research Institute of Highway, Ministry of Transportation, 2011. 